\title{
Modifications in Orthodontic Practice Post COVID Lockdown in Pakistan
}

\author{
Erum Behroz Khan ${ }^{1}$ \\ BDS, FCPS, C-Orth, MTFPDP, C-HPE \\ Mairah Shah ${ }^{2}$ \\ BDS \\ Samar Fatima ${ }^{3}$ \\ BDS \\ Zuhair Ahmed ${ }^{4}$ \\ BDS \\ Sunia Therwani ${ }^{5}$ \\ BDS \\ Sohail Khan ${ }^{6}$ \\ BDS
}

OBJECTIVE: To assess the frequency of positive changes in orthodontic practice in Pakistani governmental and private workplaces after lifting of COVID-19 lockdown.

METHODOLOGY: This cross sectional questionnaire-based study was carried out on 143 Pakistani orthodontic practitioners for the duration of 3 months. A well-constructed, computerized closed ended questionnaire was designed at an online website i.e., google drive and the link was circulated through social media and e-mail. Change in dental practice was assessed by comparing the results with CDC guidelines, keeping positive response cutoff $70 \%$. Data was analyzed by using SPSS 22, Confounders, like educational qualification, gender and workplace were controlled through stratification. Post stratification Chi square Test was applied to assess the association of dentist's response with gender, educational level, age and workplace, keeping $\mathrm{P}$ value $<0.05$.

RESULTS: There were total 143 participants ( 80 female and 63 male) with age range from 23 to 56 years, with a mean age of $31.24 \pm 6.82$ years. Majority of the participants $(75.52 \%)$ belonged to the age range of 23-33 years. Most of the orthodontists were post graduate trainees $(66.4 \%)$. Out of all these participants, 67 were working at orthodontic OPD, 22 at private practice and 51 worked at both. $68.5 \%$ Implementation of positive modifications in dental practice were recorded. The chi square test results were significant $(\mathrm{P}<.05)$ for education and workplace of orthodontist.

CONCLUSION: Most orthodontists have positively modified their dental practice post COVID-19 lockdown in Pakistan, by following WHO and CDC guidelines for Covid-19 to curtail spread of infection.

KEYWORDS: Changes, Orthodontics, COVID

HOW TO CITE: Khan EB, Shah M, Fatima S, Ahmed Z, Therwani S, Khan S. Modifications in orthodontic practice post COVID lockdown in Pakistan. J Pak Dent Assoc 2021;30(3):199-203.

DOI: https://doi.org/10.25301/JPDA.303.199

Received: 12 February 2021, Accepted: 19 May 2021

\section{INTRODUCTION}

A n outbreak of a novel coronavirus was experienced by Wuhan, an emerging business hub of China in December 2019, that killed more than eighteen hundred and infected over seventy thousand individuals

1. Vice - Principal Academics, Head, Department of Orthodontics, Saidu College of Dentistry, Saidu Sharif, Swat, KPK

2. Fellowship of College of Physicians and Surgeons part 2 Trainee, Department of Orthodontics, Sindh Institute of Oral health sciences, Karachi, Sindh, Pakistan.

3. Fellowship of College of Physicians and Surgeons part 2 Trainee, Department of Orthodontics, Sindh Institute of Oral health sciences, Karachi, Sindh, Pakistan.

4. Fellowship of College of Physicians and Surgeons part 2 Trainee, Department of Orthodontics, Sindh Institute of Oral health sciences, Karachi, Sindh, Pakistan.

5 Fellowship of College of Physicians and Surgeons part 2 Trainee, Department of Orthodontics, Sindh Institute of Oral health sciences, Karachi, Sindh, Pakistan

6. Fellowship of College of Physicians and Surgeons part 2 Trainee, Department of Orthodontics, Sindh Institute of Oral health sciences, Karachi, Sindh, Pakistan.

Corresponding author: “Dr. Erum Behroz Khan” < erumbehroz@ gmail.com > within the first fifty days of the epidemic. ${ }^{1}$ The patient's infected by the virus had symptoms of breathing difficulty, lung infection, fever and pneumonia, hence the pathogen was identified as severe acute respiratory syndrome coronavirus-2 (SARS-CoV-2). ${ }^{2,3}$ It came into view that a single animal-to-human transmission started the COVID-19 outbreak, followed by sustained human-to-human spread. Interpersonal transmission is now believed to occur mainly via respiratory droplets and contact transmission. ${ }^{4}$ The virus had spread to 113 countries and territories by 11 March 2020, with the number of registered cases reaching 118,162 and the number of deaths reaching 4290 (mortality rate $3.63 \%$ ), hence $\mathrm{WHO}$ declared coronavirus disease 2019 (COVID-19) a global pandemic. ${ }^{2,5}$

Pakistan reported it's first case of COVID-19 on 26th 
February 2020. ${ }^{2}$ Data from the COVID-19 Health Advisory Platform by Ministry of National Health Services Regulations and Coordination revealed that close to 317,595 cases have been reported so far, with approximately 6,552 deaths till date of this study. ${ }^{6}$ A provincial lockdown was instituted on March 23,2020 , to curb and restrain further spread of the disease, all non-essential movement were restricted, affecting the provision of health services. ${ }^{7}$ Ever since Pakistan lifted the lockdown in early May coronavirus cases have been growing exponentially. ${ }^{8}$ COVID-19 transmission routes, and their relative contributions, remain unknown, but this knowledge is imperative as these transmission routes determine the strategies required to protect healthcare workers from occupationally acquired infection. A research was conducted among healthcare personnel (HCP) providing care to infectious patients to explore the contributions of three transmission routes-contact, droplet, and inhalation-to the risk of COVID19 infection, the key finding was that droplet and inhalation transmission routes preponderate over the contact route, contributing $35 \%, 57 \%$, and $8.2 \%$ of the probability of infection, on average, without use of personal protective equipment. ${ }^{9}$ Due to the unique characteristics of dental procedures where a large number of droplets and aerosols could be generated, oral health professionals are vulnerable and have a higher risk of the transmission of COVID-19 between patients and dental practitioners. ${ }^{410}$ In daily clinical work, the standard protective measures are not effective enough to prevent the spread of COVID-19, especially in patients undergoing incubation period, who are unaware they are infected, or choose to hide their infection. Strict and effective infection control protocols are urgently needed for dental practices and hospitals in areas that are likely affected with COVID-19. ${ }^{4}$ The American Dental Association (ADA) took the current rapid spread of infection in consideration and highlighted key steps to be taken by dentists in addition to the standard universal precautions such as assessing signs and symptoms of respiratory tract infection; taking patient's recent travel history; recording patients' body temperature; mouth rinsing with $1 \%$ hydrogen peroxide prior to commencement of any procedure; using a rubber dam and high volume suction during procedures; and frequently cleaning and disinfecting public contact areas including door handles, chairs and, washrooms. ${ }^{11}$

A study was conducted to assess dentists knowledge about various practice modifications to combat COVID-19, in Pakistan, Saudi Arabia and other parts of the world. The study reveiled that a large number of dentists $(90 \%)$ were aware of recent modifications in the treatment protocols. However, execution of amended treatment protocol was recorded as $61 \% .^{11}$

Over the last few months, the delivery of orthodontics has rapidly changed due to COVID-19 pandemic. Routine dental services were required to close all over the world. The remaining dental care centres were suggested to restrict treatment to urgent or emergency care only, with the overarching message being to avoid aerosol generating procedures (AGPs) wherever possible. ${ }^{12}$

The aim of this study was to assess positive changes in orthodontic practice in Pakistani governmental and private workplaces after lifting of COVID-19 lockdown to prevent cross infection. If positive changes aren't being implemented, webinars and online workshops should be arranged to spread awareness.

\section{METHODOLOGY}

This study was conducted as a cross sectional questionnaire-based study, carried out on 143 dental practitioners who are currently practicing orthodontics. The duration of the study was 3 months. After obtaining ethical approval from the institute (JSMU/IRB/2020/-388). A wellconstructed computerized closed ended questionnaire was designed at an online website i.e., google drive, the study was briefly described in the questionnaire and participants were asked to sign informed consent before filling out the survey form. The online questionnaire link was circulated by principal investigator through social media and by e-mail to dental practitioners currently performing orthodontics and their responses were collected on google drive. The questionnaire comprised of 16 closed ended questions, based on a previous similar study which was used to asses knowledge and practice of dentists about COVID $19^{11}$ and Centers for Disease Control and Prevention (CDC) guidelines to collect data regarding modifications in participant's orthodontic practice post COVID lockdown. Sample size for the study was calculated by using WHO sample size calculator for single population with reported execution of amended treatment protocol recorded as $61 \%$, Absolute precision of 0.08 , Level of confidence 95\%. ${ }^{11}$ Responses were collected from 143 orthodontists who participated from all over Pakistan, change in dental practice was assessed by comparing the results with CDC guidelines, keeping positive response cutoff $70 \%$.

Inclusion criteria: Both genders were included i.e., male and female dental practitioners who are currently performing orthodontics, of all ages. Graduates or postgraduates working as orthodontists in private and hospital setting.

Exclusion criteria: Dental students, paramedical staff and dental practitioners who have practiced orthodontics for less than a year.

Data was analyzed by using SPSS 22. A Cronbach's alpha analysis was conducted on a sample of 29 responses to assess the reliability of the questionnaire. Mean and standard deviation 
was calculated for quantitative variable, age. Frequency and percentage were calculated for qualitative variables like gender, educational qualification, work place and positive/ negative responses. Confounders, like educational qualification, gender and workplace were controlled through stratification. Post stratification Chi square Test was applied to assess the association of dentist's response with gender, educational level, age and workplace, keeping $\mathrm{P}$ value $<0.05$.

\section{RESULTS}

All the data was analyzed using SPSS 22. Cronbach's analysis scale alpha level was found to be .72, which indicates that the scale has an adequate level of inter-item reliability. $68.5 \%$ implementation of positive modifications in dental practice were recorded.

There were total 143 participants, 80 female and 63 male, majority of positive responses $(35.6 \%)$ were by female orthodontists. The ages of orthodontists ranged from

Figure 1: Education of orthodontist

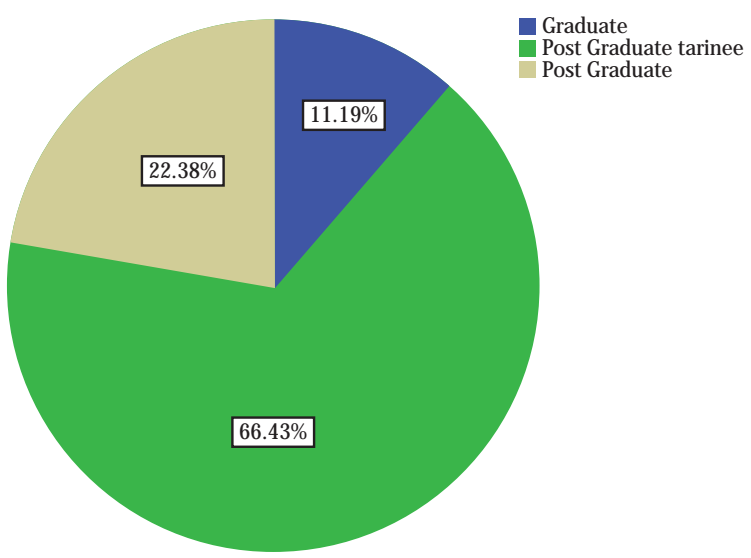

Figure 2: Frequency and percentage of workplace of orthodontists

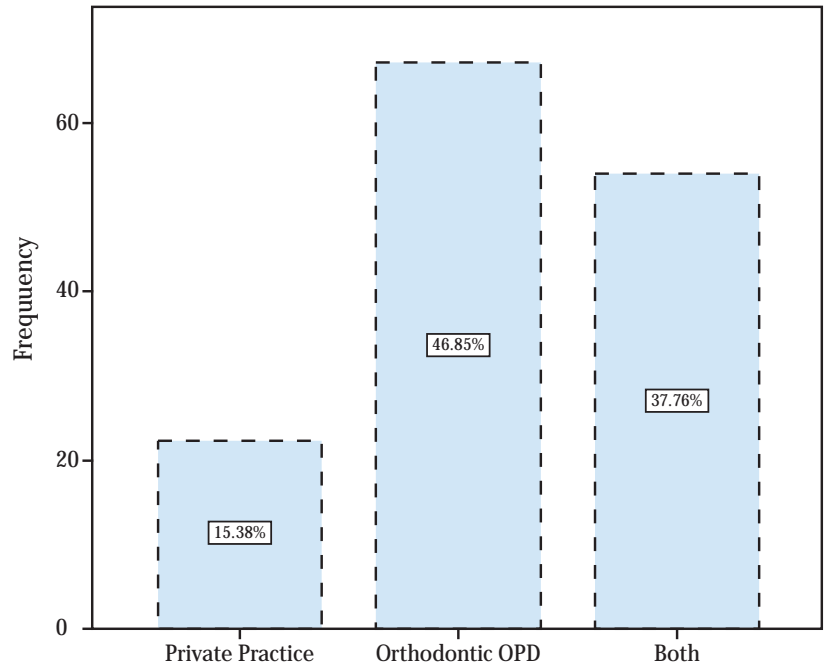

23 to 56 years, with a mean age of $31.24 \pm 6.82$ years. Majority of the participants (75.52\%) belonged to the age range of 23-33 years and had highest positive responses $(65.7 \%)$. Most of the orthodontists were post graduate trainees $(66.4 \%)$ (Figure 1). Out of all these participants, 67 were working at orthodontic OPD, 22 at private practice and 51 worked at both (Figure 2). The chi square test results were significant with $\mathrm{P} \leq .05$ for education $(\mathrm{P}=.05)$ and workplace $(\mathrm{P}=.002)$ of orthodontist, whereas no significant relationship was found between orthodontist's responses with gender $(\mathrm{P}=.20)$ and age $(\mathrm{P}=.82)$.

In Table 1, there is a description of changes in orthodontic practice post COVID lockdown in Pakistan; About $97 \%$ of orthodontists were aware of the mode of transmission of COVID-19 and 95.8\% were routinely following universal precautions of infection control such as disinfection and use of sterile instruments for every patient. About $83.9 \%$ of participants were updated with the CDC or WHO guidelines for cross-infection control regarding COVID-19 and 76.2\% asked every patient, their travel history before performing dental treatment. Moreover, $61.5 \%$ of participants were taking every patient's body temperature before performing

Table 1: Frequency and percentage of modifications in dental practice

\begin{tabular}{|c|c|c|c|c|c|}
\hline \multirow{4}{*}{$\begin{array}{c}\text { Age of } \\
\text { Orthodontist }\end{array}$} & \multirow{4}{*}{$23-33$} & \multirow{4}{*}{$\begin{array}{c}\text { Count } \\
\text { Percentage }\end{array}$} & \multicolumn{2}{|c|}{ Change } & \multirow[t]{2}{*}{ Total } \\
\hline & & & \multicolumn{2}{|c|}{ Negative Positive } & \\
\hline & & & 37 & 71 & \multirow{2}{*}{$\begin{array}{c}108 \\
100.0 \%\end{array}$} \\
\hline & & & $34.3 \%$ & $65.7 \%$ & \\
\hline & $34-44$ & Count & 8 & 17 & 25 \\
\hline & & Percentage & $32.0 \%$ & $68.0 \%$ & $100.0 \%$ \\
\hline & $45-56$ & Count & $\mathbf{0}$ & 10 & 10 \\
\hline \multirow{3}{*}{ Total } & & Percentage & $0.0 \%$ & $100.0 \%$ & $100.0 \%$ \\
\hline & & Count & 45 & 98 & 143 \\
\hline & & Percentage & $31.5 \%$ & $68.5 \%$ & $100.0 \%$ \\
\hline \multirow{4}{*}{$\begin{array}{c}\text { Gender of } \\
\text { Orthodontist }\end{array}$} & Male & Count & 16 & 47 & 63 \\
\hline & & Percentage & $25.4 \%$ & $74.6 \%$ & $100.0 \%$ \\
\hline & Female & Count & 29 & 51 & 80 \\
\hline & & Percentage & $36.3 \%$ & $63.8 \%$ & $100.0 \%$ \\
\hline \multirow[t]{2}{*}{ Total } & & Count & 45 & 98 & 143 \\
\hline & & Percentage & $31.5 \%$ & $68.5 \%$ & $100.0 \%$ \\
\hline \multirow{6}{*}{$\begin{array}{c}\text { Education of } \\
\text { the } \\
\text { Orthodontist }\end{array}$} & Graduate & Count & 2 & 14 & 16 \\
\hline & & Percentage & $12.5 \%$ & $87.5 \%$ & $100.0 \%$ \\
\hline & Post Graduate trainee & Count & 36 & 59 & 95 \\
\hline & & Percentage & $37.9 \%$ & $62.1 \%$ & $100.0 \%$ \\
\hline & Post Graduate & Count & 7 & 25 & 32 \\
\hline & & Percentage & $21.9 \%$ & $78.1 \%$ & $100.0 \%$ \\
\hline \multirow[t]{2}{*}{ Total } & & Count & 45 & 98 & 143 \\
\hline & & Percentage & $31.5 \%$ & $68.5 \%$ & $100.0 \%$ \\
\hline \multirow{6}{*}{$\begin{array}{l}\text { Workplace of } \\
\text { Orthodontist }\end{array}$} & Private Practice & Count & 2 & 20 & 22 \\
\hline & & Percentage & $9.1 \%$ & $90.9 \%$ & $100.0 \%$ \\
\hline & Orthodontic OPD & Count & 30 & 37 & 67 \\
\hline & & Percentage & $44.8 \%$ & $55.2 \%$ & $100.0 \%$ \\
\hline & Both & Count & 13 & 41 & 54 \\
\hline & & Percentage & $24.1 \%$ & $75.9 \%$ & $100.0 \%$ \\
\hline \multirow[t]{2}{*}{ Total } & & Count & 45 & 98 & 143 \\
\hline & & Percentage & $31.5 \%$ & $68.5 \%$ & $100.0 \%$ \\
\hline
\end{tabular}

dental treatment, $97.2 \%$ were deferring dental treatment of patients showing suspicious symptoms and $79 \%$ knew which authority to contact if they came across a patient with 
suspected COVID-19 infection. 38.5\% orthodontists asked every patient to rinse his/her mouth with anti-bacterial mouthwash before the treatment and $98.6 \%$ washed their hands with soap and water or used sanitizer before and after treatment of every patient. 79\% thought surgical mask wasn't enough to prevent cross-infection of Covid-19 and $83.9 \%$ thought N-95 mask or a respirator should be routinely worn in dental practice due to the COVID outbreak, hence $72.7 \%$ wore an $\mathrm{N}-95$ mask or a respirator while treating a patient in their dental practice.

About $54.5 \%$ were maintaining physical distance of 6 feet between people, in their practice and $79 \%$ wore eye protection while treating a patient. $41.3 \%$ were using high-volume suction for every patient and $60.1 \%$ properly maintained ventilation system in their practice.

\section{DISCUSSION}

The findings from this study reported, $68.5 \%$ orthodontists have adapted positive changes in their practice and have been following CDC and WHO guidelines for Covid-19 post COVID lockdown in Pakistan to prevent its cross infection.

It is essential for all orthodontists to strictly adhere to the most up-to-date recommendations from all public health authorities. If a patient needs to be treated in practice, negative history for COVID-19 symptoms should be confirmed that should include no recent travel and no contact with an infected individual. If possible, every patient should complete a screening questionnaire, before entering the practice. Infection prevention and control (IPAC) protocol and a very high quality of sterilization should be maintained in orthodontic practice, that should include following correct order for removal and replacement of PPE and hand hygiene before and after coming in contact with a patient, by washing them for at least 20 seconds with soap, as this breaks down virus's lipid layer, or alcohol-based (60\% ethanol) hand rub (ABHR) should be used. To reduce the risk of transmission, emergency orthodontic treatments for known cases of COVID-19 can be more appropriately managed in hospital setting where facilities such as air purifiers with high-efficiency particulate air filters and airborne infection isolation rooms (AIIR) with negative suction are available. After completion of any emergency orthodontic treatment meticulous disinfection should be carried out to curtail spread through fomites and surrounding surfaces. ${ }^{13}$

The demographic information of the participants demonstrates that majority of responses $95(66.4 \%)$ were from post graduate trainees and the remaining 32(22.4\%) were from postgraduates and 16(11.2\%) were from graduates. Out of 143 participants, 80 were female $(55.9 \%)$ and 63 were male $(44.1 \%)$. The age ranged from 23-56 and was further divided into three categories, with $108(75.5 \%)$ participants falling between age range 23-33, 25(17.5\%) between 34-44 and 10(7\%) between 45-56. Most of the participants $67(46.9 \%)$ worked at hospital setting i.e., orthodontic OPD, 22(15.4\%) worked at private practice and $54(37.8 \%)$ worked at both private setting and orthodontic OPD.

A previous multinational study was conducted to assess Knowledge, Attitudes and Practices of dental practitioners regarding the COVID-19 pandemic with majority of responses from Asian continent that demonstrated, most dentists with degree of MDS, BDS and DDS had good knowledge and practice scores. ${ }^{14}$ A similar study conducted in Pakistan, showed mean knowledge score significantly differed between general dentists $(16.55 \pm 2.36)$ and dental specialists $(17.15 \pm 2.04) .{ }^{15}$ Our study further supports this data with majority of positive responses from postgraduate trainees.

Table 2 illustrates, positive modifications in treatment protocols were mostly found to be adapted by female

Table 2: Cross tabulation of orthodontist's responses with age, gender, education and workplace of orthodontist

\begin{tabular}{|c|c|c|c|c|}
\hline & & YES (\%) & NO (\%) & $\begin{array}{l}\text { DON'T } \\
\text { KNOW } \\
(\%)\end{array}$ \\
\hline 1 & $\begin{array}{l}\text { Are you aware of the mode of } \\
\text { transmission of COVID-19? }\end{array}$ & $\begin{array}{c}140 \\
(97.9 \%)\end{array}$ & $3(2.1 \%)$ & 0 \\
\hline 2 & $\begin{array}{l}\text { Are you updated with the current CDC } \\
\text { or WHO guidelines for cross-infection } \\
\text { control regarding COVID-19? }\end{array}$ & $\begin{array}{c}120 \\
(83.9 \%)\end{array}$ & $14(9.8 \%)$ & $9(6.3 \%)$ \\
\hline 3 & $\begin{array}{l}\text { Are you currently asking every } \\
\text { patient's travel history before } \\
\text { performing dental treatment? }\end{array}$ & $\begin{array}{c}109 \\
(76.2 \%)\end{array}$ & $30(21 \%)$ & $4(2.8 \%)$ \\
\hline 4 & $\begin{array}{l}\text { Are you currently taking every } \\
\text { patient's body temperature before }\end{array}$ & $88(61.5 \%)$ & $55(38.5 \%)$ & 0 \\
\hline 5 & $\begin{array}{l}\text { Are you deferring dental treatment of } \\
\text { patients showing suspicious symptoms? }\end{array}$ & $\begin{array}{c}139 \\
(97.2 \%)\end{array}$ & $4(2.8 \%)$ & $\mathbf{0}$ \\
\hline 6 & $\begin{array}{l}\text { Do you think surgical mask is enough to } \\
\text { prevent cross-infection of COVID-19? }\end{array}$ & $25(17.5 \%)$ & $113(79 \%)$ & $5(3.5 \%)$ \\
\hline 7 & $\begin{array}{l}\text { Do you think N-95 mask or a } \\
\text { respirator should be routinely worn in } \\
\text { dental practice due to the current } \\
\text { outbreak? }\end{array}$ & $\begin{array}{c}120 \\
(83.9 \%)\end{array}$ & $18(12.6 \%)$ & $5(3.5 \%)$ \\
\hline 8 & $\begin{array}{l}\text { Have you ever worn an } \mathrm{N}-95 \text { mask or a } \\
\text { respirator while treating a patient in } \\
\text { your dental practice? }\end{array}$ & $\begin{array}{c}104 \\
(72.7 \%)\end{array}$ & $37(25.9 \%)$ & $2(1.4 \%)$ \\
\hline 9 & $\begin{array}{l}\text { Do you routinely follow universal } \\
\text { precautions of infection control such as } \\
\text { disinfection and use of sterile } \\
\text { instruments for every patient? }\end{array}$ & $\begin{array}{c}137 \\
(95.8 \%)\end{array}$ & $5(3.5 \%)$ & $1(0.7 \%)$ \\
\hline 10 & $\begin{array}{l}\text { Are you currently maintaining physical } \\
\text { distance (6 feet between people) in your } \\
\text { practice? }\end{array}$ & $78(54.5 \%)$ & $55(38.5 \%)$ & $10(7 \%)$ \\
\hline 11 & $\begin{array}{c}\text { Do you wear eye protection while } \\
\text { treating a patient in your dental } \\
\text { practice? }\end{array}$ & $113(79 \%)$ & $28(19.6 \%)$ & $2(1.4 \%)$ \\
\hline 12. & $\begin{array}{l}\text { Do you use high-volume suction in your } \\
\text { practice for every patient? }\end{array}$ & $59(41.3 \%)$ & $81(56.6 \%)$ & $3(2.1 \%)$ \\
\hline 13. & $\begin{array}{l}\text { Do you properly maintain ventilation } \\
\text { system in your practice? }\end{array}$ & $86(60.1 \%)$ & $47(32.9 \%)$ & $10(7 \%)$ \\
\hline 14. & $\begin{array}{l}\text { Do you ask every patient to rinse } \\
\text { his/her mouth with anti-bacterial } \\
\text { mouthwash before treatment? }\end{array}$ & $55(38.5 \%)$ & $86(60.1 \%)$ & $2(1.4 \%)$ \\
\hline 15 & $\begin{array}{l}\text { Do you wash hands with soap and } \\
\text { water/use sanitizer before and after } \\
\text { treatment of every patient? }\end{array}$ & $\begin{array}{c}141 \\
(98.6 \%)\end{array}$ & $2(1.4 \%)$ & 0 \\
\hline 16 & $\begin{array}{l}\text { Are you aware of which authority to } \\
\text { contact if you come across a patient } \\
\text { with suspected COVID-19 infection? }\end{array}$ & $113(79 \%)$ & $24(16.8 \%)$ & $6(4.2 \%)$ \\
\hline
\end{tabular}


orthodontist (51), orthodontist between age range 23-33 (71), Postgraduate trainees (59) and orthodontists who are worked at both workplace settings (41). A similar study was conducted in turkey, to assess the impact of the novel Coronavirus, positive associations between increased knowledge level and factors such as being a woman, working in a university hospital were determined..$^{16}$ Our study supports this data with more positive responses from female orthodontists.

Limitations of this study were time constraint due to increasing changes in the severity of the Covid situation and small sample size.

\section{CONCLUSION}

Most orthodontists working in governmental and private setting have positively modified their dental practice post COVID-19 lockdown in Pakistan, by following WHO and CDC guidelines for COVID-19 to curtail spread of infection. With the rapidly evolving COVID-19 situation, orthodontic practitioners should adhere to the most up to date recommendations from all public health authorities.

\section{COMPETING INTERESTS}

Authors have declared that no competing interests exist.

\section{REFERENCES}

1. Shereen MA, Khan S, Kazmi A, Bashir N, Siddique R. COVID-19 infection: Origin, transmission, and characteristics of human coronaviruses. J Advanced Res. 2020;24:91-8.

https://doi.org/10.1016/j.jare.2020.03.005

2. Saqlain M, Munir MM, ur Rehman S, Gulzar A, Naz S, Ahmed Z, et al. Knowledge, attitude, practice and perceived barriers among healthcare professionals regarding COVID-19: A Cross-sectional survey from Pakistan. J Hospital Infection. 2020;105:419-23. https://doi.org/10.1101/2020.04.13.20063198

3. Trivedi M. Covid-19: Impact and Dealings in Orthodontic Practice Design Post Viral Outbreak and Lockdown. Biomed Pharmacol J. 2020;13:1387-91

https://doi.org/10.13005/bpj/2008

4. Meng L, Hua F, Bian Z. Coronavirus disease 2019 (COVID-19): emerging and future challenges for dental and oral medicine. J Dent Res. 2020;99:481-87.

https://doi.org/10.1177/0022034520914246

5. Saqlain M, Munir MM, Ahmed A, Tahir AH, Kamran S. Is Pakistan prepared to tackle the coronavirus epidemic? Drugs \& Therapy Perspectives. 2020;20:1-2.

https://doi.org/10.1007/s40267-020-00721-1
6. COVID-19 Health Advisory Platform by Ministry of National Health Services Regulations and Coordination. Available at: http://covid.gov.pk/ [last accessed October 2020]

7. Chandir S, Siddiqi DA, Setayesh H, Khan AJ. Impact of COVID-19 lockdown on routine immunisation in Karachi, Pakistan. The Lancet Global Health. 2020;8:e1118-e20.

https://doi.org/10.1016/S2214-109X(20)30290-4

8. Hassan S, Qureshi HA, Gul M. COVID-19 Second Phase Lockdown Option and Public Opinion: A case study in Pakistan. Int J Med Sci Clin Res Review. 2020;3:316-24.

9. Jones RM. Relative contributions of transmission routes for COVID-19 among healthcare personnel providing patient care. J of Occupational and Environmental Hygiene. 2020;17:408-15. https://doi.org/10.1080/15459624.2020.1784427

10. Bhumireddy J, Mallineni SK, Nuvvula S. Challenges and possible solutions in dental practice during and post COVID-19. Environmental Science and Pollution Research. 2020;7:1-3.

https://doi.org/10.1007/s11356-020-10983-x

11. Ahmed MA, Jouhar R, Ahmed N, Adnan S, Aftab M, Zafar MS, et al. Fear and practice modifications among dentists to combat Novel Coronavirus Disease (COVID-19) outbreak. Int J Environmental Res Public Health. 2020;17:2821 (1-11).

https://doi.org/10.3390/ijerph17082821

12. Llandro H, Allison J, Currie C, Edwards D, Bowes C, Durham J, et al. Evaluating aerosol and splatter during orthodontic debonding: implications for the COVID-19 pandemic. medRxiv. 2020. https://doi.org/10.31219/osf.io/djcus

13. Suri S, Vandersluis YR, Kochhar AS, Bhasin R, Abdallah MN. Clinical orthodontic management during the COVID-19 pandemic. The Angle Orthodontist. 2020;90:473-84.

https://doi.org/10.2319/033120-236.1

14. Kamate SK, Sharma S, Thakar S, Srivastava D, Sengupta K, Hadi AJ, Chaudhary A, Joshi R, Dhanker K. Assessing Knowledge, Attitudes and Practices of dental practitioners regarding the COVID-19 pandemic: A multinational study. Dental and Medical Problems. 2020;57:11-7. https://doi.org/10.17219/dmp/119743

15. Almas K, Khan AS, Tabassum A, Nazir MA, Afaq A, Majeed A. Knowledge, Attitudes, and Clinical Practices of Dental Professionals during Coronavirus Disease 2019 (COVID-19) Pandemic in Pakistan. Eur J Dent. 2020;14(SOI):S63-S69.

https://doi.org/10.1055/s-0040-1718785

16. Sezgin GP, Sirinoglu Çapan B. Assessment of dentists' awareness and knowledge levels on the Novel Coronavirus (COVID-19). Brazil Oral Res. 2020;34.e112

https://doi.org/10.1590/1807-3107bor-2020.vol34.0112 